\title{
Achieving sustainable governance of horizontal integration of care services: progress and democratic accountability of strategic coordination bodies for older people
}

\author{
Stefan Szücs and Inger Kjellberg \\ Department of Social Work, University of Gothenburg, Gothenburg, Sweden
}

\begin{abstract}
Purpose - The purpose is to analyse the relationship between democratic accountability and how sustainable governance is achieved by horizontally integrating care services for older people through collaboration in a coordination body of key leaders from across the health and social care system.

Design/methodology/approach - The data and measures come from two surveys with coordination body members in Sweden (politicians, administrators, professionals) from a sample of 73 bodies in $2015(n=549)$ and the same/corresponding 59 bodies in $2019(n=389)$.

Findings - The governance of integrating care scale and the accountability scales repeatedly show consistency among individual members. Systematic progress is found among large coordination bodies: the greater the average perception of governance of horizontally integrating care in 2015, the greater it was in 2019 - and regardless of the period, the stronger the internal administrative or political monitoring and reviewing of the coordination body, the greater its governance (while the relationship to the external monitoring and reviewing is weak). However, the growing importance of external accountability is indirect, shown by stronger correlations between the internal political and external monitoring and reviewing, regardless of size.

Research limitations/implications - The scales are based on self-reported perceptions that cannot be objectively verified, but they can be linked to changes in outcomes and user experiences in the later stages of the research.

Originality/value - Repeatedly verified scales of internal and external accountability for analysing and evaluating governance of integrating care services horizontally, which is useful for improving strategic coordination of integrated care.
\end{abstract}

Keywords Integrated care, Older people, Collaboration, Coordination bodies, Governance, Accountability Paper type Research paper

(C) Stefan Szücs and Inger Kjellberg. Published by Emerald Publishing Limited. This article is published under the Creative Commons Attribution (CC BY 4.0) licence. Anyone may reproduce, distribute, translate and create derivative works of this article (for both commercial and non-commercial purposes), subject to full attribution to the original publication and authors. The full terms of this licence may be seen at http://creativecommons.org/licences/by/4.0/legalcode

In addition to the anonymous referees, the authors would like to thank the members of all coordination bodies strategically integrating eldercare in Sweden who completed the surveys between 2014 and 2019. We are also very grateful to Jana Sandman for her work with all the surveys, and Statistics Sweden for the fieldwork of the 2019 survey. Parts of this paper were first presented at the Nordic Political Science Association Congress in Gothenburg 2014 and Odense 2017, and in 2018 at the European Consortium for Political Research (ECPR) General Conference in Hamburg, and the European Group of Public Administration (EGPA) Annual Conference in Lausanne. The research was funded by the Swedish Research Council for Health, Working Life and Welfare (Forte): Research Programme on the Quality, Organization, and Processes of Welfare (project reference number 2017-02119, "Sustainable Quality Coordination - How to Coordinate Governance of Social Services and Health Care for Frail Older Persons").

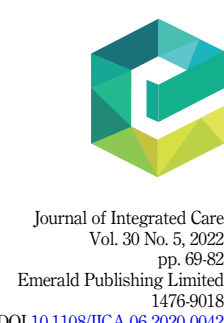

DOI 10.1108/JICA-06-2020-0042 
JICA
30,5

\section{Introduction}

Integrating care services from the political and strategic perspective of the policy-maker is ultimately defined as: "Initiatives seeking to improve outcomes for those with (complex) chronic health problems and needs by overcoming issues of fragmentation through linkage or coordination of services of different providers along the continuum of care." (Nolte and Pitchforth, 2014, p. 6). Evidence suggests that a key initiative to resolve the issues surrounding care for older people - when they live with multi-morbidity - on a strategic level is collaboration by stakeholders involved in horizontal (rather than vertical) care integration firmly centred on the older person which pays close attention to the implementation of integrated care (see correspondence in Harvey et al., 2019). In theory, however, there are three additional, more vertical, ways to achieve such public sector coordination - by hierarchy, markets and networks - and perhaps the most important reason for questioning its efficacy is that of democratic accountability (Peters, 2015, p. 140). In principle, such democratic accountability is defined as an inner or external check carried out through the political, administrative, and/or organisational mechanisms of monitoring and reviewing (Jackson, 2009; Bovens, 2010). Recent research by Cooper and Grubnic (2018, p. 1) on key leaders across the health and social care systems collaborating strategically through such coordination bodies - Health and Wellbeing Boards in England (HWBs) - warns us that vertical policy initiatives "contribute to uncertainty that can hinder the progress of HWBs". After studying the progress of democratic accountability in two such cases, and due to the required legal creation of HWBs in 2012 to provide strategic governance for health outcomes for localities across England, Cooper and Grubnic (2018, p. 5) conclude that "any increase in democratic accountability has been indirect and limited". Two accountability types were found. The first is based on an inner or internal check, labelled as "horizontal accountability to fellow board members", and the second is based on an external check, described as "more vertical, upward accountability" (Cooper and Grubnic, 2018, pp. 4-5). However, the more complex the coordination becomes, the greater the difficulties will be in tracking responsibility for its achievement (Olsen, 2015), and even answer basic questions of who governs and how well. Little is known about the long-term effects of internal and external democratic accountability - across several periods of vertical policy change - in achieving sustainable governance through horizontal integration of care services in strategic coordination bodies. Sweden is particularly interesting from this perspective, with its decentralised system of integrating local social services (290 municipality councils) and regional health care (21 county councils) for older people, achieved through horizontal collaboration in strategic coordination bodies monitored and reviewed by internal checks but increasingly challenged by market, hierarchy and network coordination. The aim of collaborating in a coordination body is to strategically coordinate the governance of integrating care as comprehensively and efficiently as possible to satisfy multiple constituencies and all other stakeholders involved. Although the body has no decision-making power (except in one case), it acts as a link between governance and the local implementation of health and social care for older people. Previous research has demonstrated that these coordination bodies contain politicians or administrators with or without health/social care professionals and pensioner organisation representatives, and achieve integrated care depending on their internal administrative or political monitoring and reviewing (Szücs, 2018a).

\section{Background}

There have been four shifts in the Swedish politics of eldercare policy coordination (Figure 1). Previous research has demonstrated that the first shift towards the current system of pursuing horizontal management of eldercare by collaboration occurred after the 1991 general election, when the government went from social democratic to centre-right bloc rule 


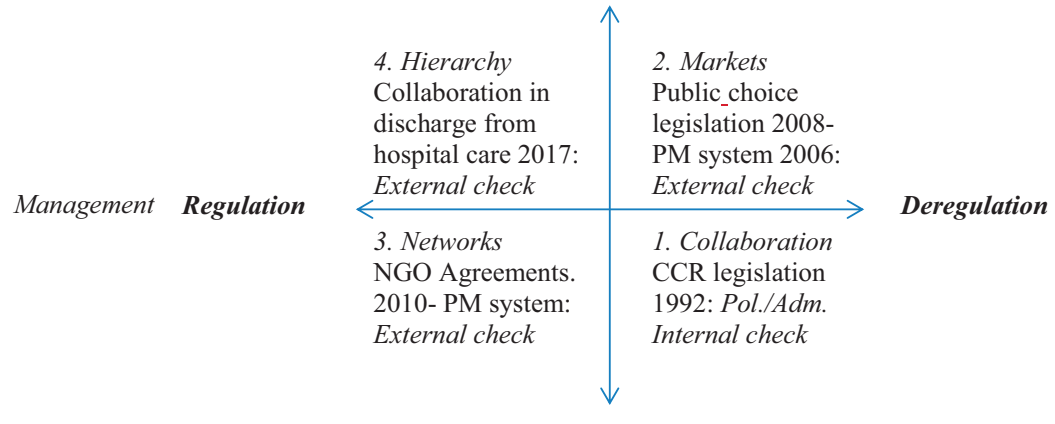

Decentralisation - Horizontal integration
Figure 1. Politics and management to coordinate and check integrated care in Sweden

(Szücs, 1995). The 1992 Community Care Reform (CCR) paved the way for the present model of decentralisation and deregulation of eldercare (Ahgren and Axelsson, 2011; Meagher and Szebehely, 2013a). Since then, the regional authority has been responsible for medical expertise and health care, and the local authority for social care, including home and residential care for older people, but how this collaboration should be achieved and internally checked by coordination bodies has been left to the local authorities and regions themselves to decide. The second shift occurred after the 2006 general election, as the government went from social democratic to centre-right bloc rule for the second time, and a model of vertical coordination by markets was introduced (Anell et al., 2012; Meagher and Szebehely, 2013b). Since then, through a mix of centralised politics and deregulated new public management (NPM), national authorities have enabled coordination by the Public Choice Legislation Act (2008), forcing regional governments to implement "a market" for primary health care (from 2008) and give incentives to local governments to implement corresponding local markets for eldercare (from 2009). Within this deregulated but centralised system, care for older people has been subject to an external check since 2006 through national state performance management (PM) systems. The third shift came after the 2010 general election, with the alliance of the centre-right bloc government remaining in power. This time there was a decentralisation of politics to try to improve the external check regulation of the national PM system through central agreements with non-government organisations (NGOs) coordinated through networks (S2011/11027/FST). The latest and fourth shift came into effect after the return of social democratic rule in the 2014 and 2018 general elections (SOU, 2016; Szücs, 2018b). It paved the way for increasing the hierarchy through further centralisation and regulation with the new Collaboration in Discharge from Hospital Care Act (2017). Previous research has demonstrated that this most recent restructuring of the Swedish care system for older people with complex needs represents a paradox, as stakeholders simultaneously demand both centralisation and decentralisation through collaboration on a local basis (Kjellberg and Szücs, 2020).

The specific case examined in this article is the long-term progress of achieving collaborative integrated care for older people by strategic coordination bodies under the influence of centralisation through full-scale market initiatives, hierarchy and decentralised 
JICA 30,5

network regulation. A recent, but rare, example of such a long-lasting, successful achievement from collaborative initiatives comes from a case study of a coordination body in Sweden managing the governance of integrated health and social care within an urban regional area with a population of 100,000 inhabitants (Klinga et al., 2018). This case study demonstrated the dynamics of sustainability and change due to seven indicators of integrated care during a 20-year period. These indicators included clear collaborative objectives, well-defined target groups for intervention, learning through good communication, consensus on service performance, well-adapted strategic-operative leadership trust-based implementation and participatory quality gains. Beyond this, and many other case studies (see overview in Klinga et al., 2018), however, little is known about how to measure and systematically explain why some collaborative initiatives succeed and others fail to achieve long-term progress in integrated care. Furthermore, whether collaborative integrated care is achieved well or poorly is hard to explain without knowledge about the impact by those responsible for monitoring and reviewing the system. The purpose of this paper is to analyse how sustainable governance can be achieved by horizontally integrating care services for older people through collaboration in coordination bodies. The research questions are: How is collaboration on integrating care governance for older people systematically achieved and sustained? How have monitoring and reviewing of horizontal collaboration changed (due to increasing regulation and vertical coordination of health system policy through hierarchy, markets, and networks)? Why do some collaborations on integrating services succeed and others fail?

This paper presents results from the governance of the same or corresponding coordination bodies evaluated in the beginning of 2015 for the 2011-2014 period and in the beginning of 2019 for the 2015-2018 period (i.e. across two local and regional government terms of office). The study provides a rare opportunity to study the degree to which coordination body members embrace approaches suggested to promote collaborative working between all the stakeholders dependent on accountability by various forms of internal and external checks by the coordination body.

The study was approved by the Regional Ethics Committee (Gothenburg No, 587-18) in August 2018.

\section{Methods}

After stratified random sampling of one-third of the 290 local authorities' collaboration with the 21 regional authorities and all other stakeholders involved in their coordination bodies, the two coordination body surveys followed the same methodology. The sample of relevant respondents from the 2015 survey included 870 members (981, of which 62 could or would not participate or overlapped, and 49 could not be reached) in 73 coordination bodies integrating health and social care for older people across Sweden. The response rate was $63 \%(n=549)$, with a survey response from all the sampled coordination bodies. The sample of relevant respondents from the same or corresponding coordination bodies in the 2019 survey included 783 persons (888, of which 21 overlapped and 84 could not be reached), with a response rate of $50 \%(n=389)$, with participation from all 59 remaining or corresponding bodies (Table 1 ).

The number of coordination bodies decreased from 73 to 59 between the 2011-14 and 2015-18 periods. Of the 59 bodies surveyed in 2019, 26 were unchanged, 19 had changed at least their name and 14 were new in terms of organisation and name (Table 2). Two trends of change explain the reduction in coordination bodies. First, some of the coordination bodies have broadened their scope of target groups, from just being a strategic body for coordinating health and social care for older people in 2011-14 to also including other groups with complex needs, such as children and young people, or others with disability care in 2015-18. Second, many of the small coordination bodies (10 or fewer members), in particular, have disappeared 
as a consequence: from 30 in 2015 to 15 in 2019 (Table 3). Despite the lower response rate $(13 \%$ units), many organisational changes and new bodies compared with the 2015 survey, the central characteristics of the samples of respondents are quite similar (Table 4).

The survey with its instruments is a new tool that was piloted in the beginning of 2014. It started being used for fieldwork in the beginning of 2015 and 2019 (as reported in Szücs, 2018a). The postal addresses of the members of the coordination bodies were collected by the research assistant who also carried out the 2014-15 fieldwork, including all the coding into SPSS for the first wave of the survey. The corresponding fieldwork for the second wave was carried out by Statistics Sweden (SCB) and accompanied by a technical report evaluation of the tool before and after sending out the survey, as well as the code book with a list of variables for the SPSS file. The survey questionnaire contained questions divided into sections - about staffing and representation, working modes, missions and objectives, quality of care coordination, perceptions of democratic accountability and statements about the coordination body (governance). The fieldwork did not start until after mandatory approval of the survey design and questionnaire by the Swedish Association of Local and Regional Authorities (SALAR), as required by Swedish law. The variables of the sampled coordination bodies and their members (respondents) were identified and mapped to the survey data (by Statistics Sweden during the second wave) by linking them to information about the respondent's organisational affiliation, her/his organisational position/title and the name of the coordination body. The survey was sent with an introductory letter/reminder addressing each respondent and the affiliated name of the coordination body of which she/he was a member. Coordination bodies are treated anonymously (shown only by a fictive number; see Figure 2). The survey could be used in neighbouring Scandinavia, or similar countries. The questionnaire as edited by Statistics Sweden (SCB) is available upon request in

\begin{tabular}{llccc}
\hline Survey year & Data-collection period & $\begin{array}{c}\text { Mailing list } \\
N\end{array}$ & $\begin{array}{c}\text { Participants } \\
n\end{array}$ & $\begin{array}{c}\text { Response rate } \\
\%\end{array}$ \\
\hline 2015 & January-April 2015 & $981-111=870$ & 549 & 63 \\
2019 & January-April 2019 & $888-105=783$ & 389 & 50
\end{tabular}

Note(s): ${ }^{a}$ Total sample minus net sample equals active members of coordination bodies for older people

\section{Horizontal integration of care services}

Table 1

Data collection periods and sample sizes for the two coordination body surveys

\begin{tabular}{lcccc}
\hline & $\begin{array}{c}\text { Coordination bodies } \\
\text { Period years }\end{array}$ & $\begin{array}{c}\text { Unchanged }^{\mathrm{a}} \\
n\end{array}$ & $\begin{array}{c}\text { New name }^{\mathrm{a}} \\
n\end{array}$ & $\begin{array}{c}\text { New organisation }^{\mathrm{a}} \\
n\end{array}$ \\
\hline $2011-14$ (2015 survey) & 73 & & & 14 \\
$2015-18(2019$ survey) & 59 & 26 & 19 & 14
\end{tabular}

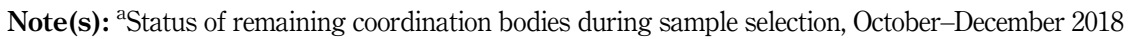

Table 2.

Periods covered and sampled coordination body stability and change

\begin{tabular}{|c|c|c|c|c|}
\hline Period years & $\begin{array}{c}\text { Total } \\
n\end{array}$ & $\begin{array}{c}\text { Small }^{\mathrm{a}} \\
n\end{array}$ & $\begin{array}{c}\text { Medium-sized }^{\mathrm{b}} \\
\end{array}$ & $\begin{array}{c}\text { Large }^{c} \\
n\end{array}$ \\
\hline 2011-14 (2015 survey) & 73 & 30 & 14 & 29 \\
\hline 2015-18 (2019 survey) & 59 & 15 & 17 & 27 \\
\hline
\end{tabular}

Note(s): ${ }^{\mathrm{a}} 10$ or fewer members of the coordination body, ${ }^{\mathrm{b}} 11$ to 15 members of the coordination body, ${ }^{\mathrm{c}} 16$ members or more of the coordination body

Table 3. Size of the sampled coordination bodies (size by number of members) 
Coordination body characteristics

Coordination body

Size: average number of members

Member experience: average number of

36 years

\section{4}

Type of mandate/representation

Local government representative

Regional government representative

Non-government private/civic representative

Local-regional association representative

Individual member characteristics

Politician

Administrator

Professional

Gender

Female

Dependent and independent variable scales (1-4)

Governance of integrating care services

External check (multiple institutions) ${ }^{\mathrm{a}}$

Internal administrative check (multiple authorities) $^{\mathrm{a}}$

Internal political check (multiple constituencies) $^{\mathrm{a}}$

39

5.16

(389)

4.00

(309)

(215)

(13)

(128)

(359)

(379)

(534)

(339)

(377)

2.35

57

38

3

(9)

(8)

2

(83)

3.29

1.70

2.80

and review) characteristics by survey year

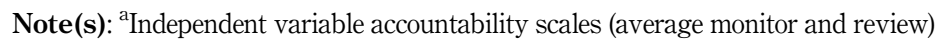

Swedish, and the research project's planned webpage (https://www.gu.se/forskning/sqAsustainable-quality-coordination-how-to-coordinate-governance-of-social-services-andhealth-care-for-frail-older-persons) will include a translated version.

All analyses were made in IBM SPSS 25. The scales were tested with Cronbach's Alpha, which is a measure of scale reliability, providing evidence of internal consistency of different aspects of a phenomenon, that is how closely related a set of variables are in describing such a construct, ranging from zero to one, with 0.70 being acceptable ( $N$ represents the number of valid cases, i.e. respondents). The multiple regression analysis is done by Ordinary Least Squares (OLS), based on Enter, that is a procedure for variable selection in which all variables in a block are entered in a single step into the analysis, starting with Model 1, then all the variables in a block for Model 2 are added and a comparison is made of the effect of these on the power of block1, and so forth.

The concepts of the dependent and independent variables were defined based on theory advanced in this paper, findings from previous research and in consultation with the Swedish Association of Local and Regional Authorities (SALAR) before each of the two waves of the longitudinal study. The respondents did not know which questions/items in the questionnaire were related to the scales of the dependent and independent variables.

The dependent variable: the governance of integrating care services scale

The measure was based on the following. The respondents were asked to "Please consider the following statements about the coordination body that you are a member of". They were then asked to rate the statements on a scale from 1 (strongly agree) to 4 (strongly disagree; items reversed). The statements were: "The coordination body has a clear purpose of integrating" 
Horizontal integration of

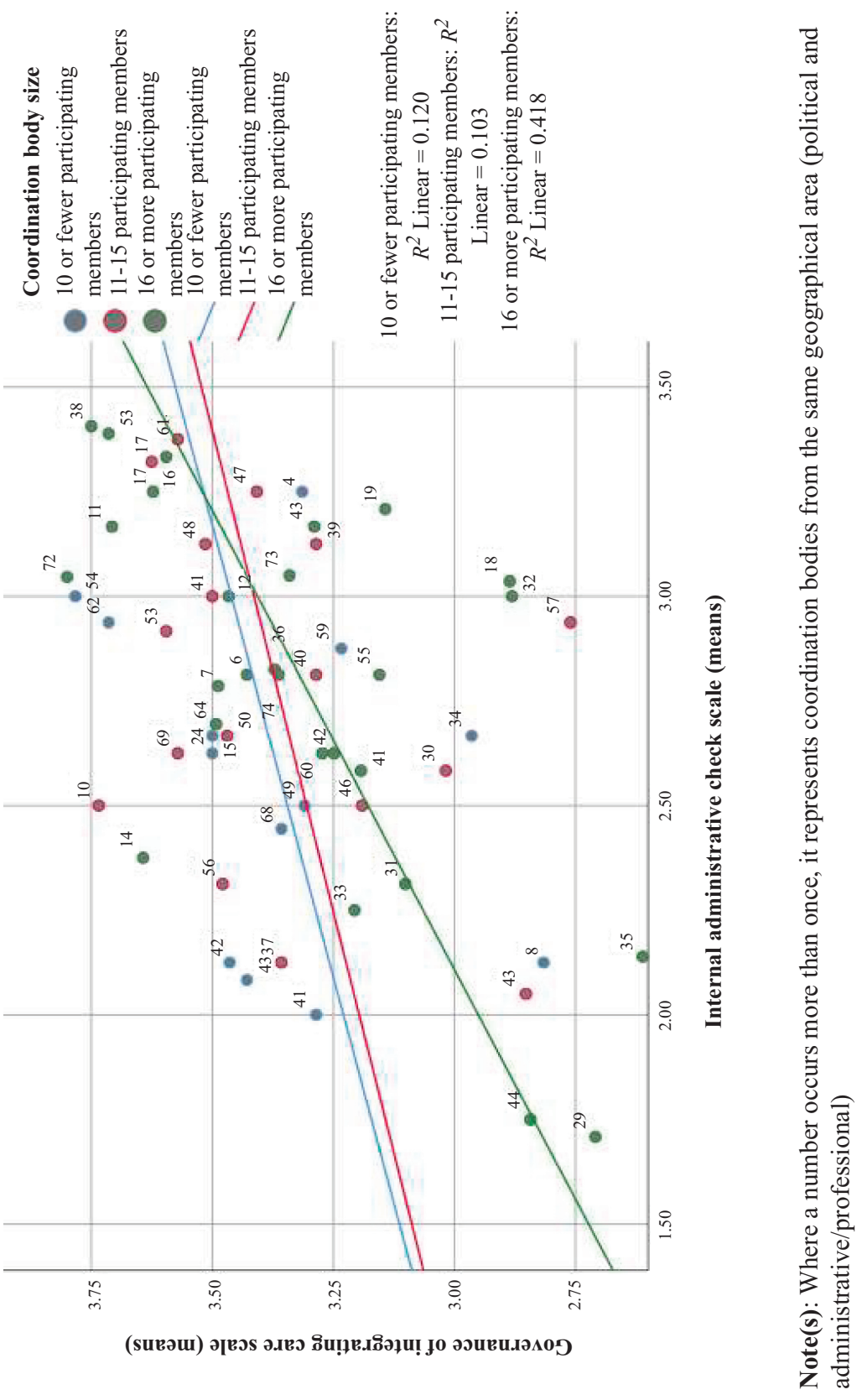

75

Figure 2. Internal administrative check and governance of integrating care services 2015-18 
JICA

30,5

(care); "The coordination body has a well-defined target group for integrating" (care); "The work in the coordination body is characterised by good communication"; "There is good consensus in the coordination body on how to implement the performance of integrated care for older people with complex needs"; "There is well-adapted leadership for the tasks of the coordination body"; "I trust that the decisions and agreements made by the coordination body are implemented" and "There are great quality gains from taking part in your coordination body for older people with complex needs". Cronbach's Alpha 2015 is $0.83(n=478)$ and for 2019 it is $0.84(n=374)$.

\section{Independent variables}

The three accountability measures were based on items from the following question: "To what degree do the following operators monitor and review work of the coordination body?" Respondents were asked to rate the following statements on a scale from 1 (to a very high degree) to 4 (to a very low degree/not at all; items reversed). The statements for the internal administrative check scale were: "Managers of local social services"; "Regional top management"; "Regional Primary Health Care (PHC) management" and "Regional hospital/ specialist health care management". Cronbach's Alpha 2015 is $0.84(n=268)$ and for 2019 it is $0.85(n=188)$. The statements for the internal political check scale were: "Top local government politicians (Council and Executive board)"; "Local government board members (for example social welfare board)" and "Regional/County government politicians". Cronbach's Alpha 2015 is $0.88(n=267)$ and for 2019 it is $0.80(n=197)$. The statements for the external check scale were: "Inspection authorities/audit agencies"; "Health care/social inspectorates"; "Relatives" and "Media". The Cronbach's Alpha 2015 is $0.91(n=267)$ and for 2019 it is $0.89(n=197)$.

\section{Controls}

Coordination body: Size (number of members/participants), Member experience (number of years as a member). Type of mandate/representation: Local government, Regional government, Non-government private/civic, Local-regional association representative (reference indicator). Individual member: Politician, Administrator, Professional health or social care frontline worker (reference indicator), Gender (female $=1$, male $=0$ ). Additional controls could include hierarchy and position of individual members as administrators, professionals or politicians.

\section{Results}

How the governance of integrating care services for older people is achieved and sustained Multivariate regression analysis from the initial 2015 survey shows that the association between the integrating care services scale and the internal political and administrative check remains quite strong when controlled for coordination body and individual member characteristics (Table 5). Model 1 shows that among the coordination body characteristics, only size (number of members) significantly determines the level of achieving governance of integrating care services for older people according to the respondents. The association is negative $(-0.20)$, which indicates that the smaller the coordination body, the stronger the perception of integration of care. Adding individual member characteristics from Model 2 into the analysis, such as being a politician, administrator or professional - or being a woman (gender, non-significant correlation) - does not change the association between size and reported successful integrating. However, the variance in integrating care services explained by Models 1 and 2 is only $2 \%$. Nevertheless, when accountability is introduced into the analysis in Model 3, the variance explained increases to $15 \%$, and there are strong 
JICA 30,5

\section{8}

integrating care services for older people by horizontal collaboration of the coordination body. However, such long-term progress of the association between integrating care services and the external check from vertical integration does not exist; the correlations are low and statistically non-significant. Instead, there is a growing dependence, especially between the external and internal administrative check, increasing from 0.26 in 2015 to 0.39 in 2019 (particularly among large bodies, at 0.66 ) and regardless of size, the relationship between the external and internal political check of the coordination body increases from 0.50 in 2015 to 0.64 in 2019 (Table 6).

\section{Why some governance collaboration on integrating services succeed and others fail}

Successfully integrated health care systems require 5-8 years to materialise in the programme (Dickinson, 2014; Goodwin et al., 2012). The analyses of this paper have demonstrated that such long-term success in achieving sustainable governance of integrated care for older people in Sweden is found among previously more successful, large coordination bodies, which are held to account to a higher degree by the collaborating members themselves through the internal check. Thus, in theory, this kind of sustainable governance of integrating care may occur because of path dependency, the internal check of the collaborative working and the mere size of the coordination body (regardless of its budget) allowing many, if not all, stakeholders to pay close attention to implementation. But why do some of these succeed and others fail? Looking at the scatter plot of coordination bodies (Figure 2), among the large collaborations, one of the most successful in achieving sustainable governance of integrating care (as defined by this study) is number 38 , and the least successful are numbers 44, 35 and 29, all of which belong to the same region. While coordination body 38 represents a geographical area known for its truly integrated care

\begin{tabular}{|c|c|c|c|c|c|c|c|c|}
\hline \multirow[b]{2}{*}{ Democratic accountability } & \multicolumn{2}{|c|}{$\begin{array}{l}\text { Governance of } \\
\text { integrating care } \\
\text { services scale }\end{array}$} & \multicolumn{2}{|c|}{$\begin{array}{l}\text { External check } \\
\text { scale }\end{array}$} & \multicolumn{2}{|c|}{$\begin{array}{c}\text { Internal } \\
\text { administrative } \\
\text { check scale }\end{array}$} & \multicolumn{2}{|c|}{$\begin{array}{c}\text { Internal } \\
\text { political } \\
\text { check scale }\end{array}$} \\
\hline & 2015 & 2019 & 2015 & 2019 & 2015 & 2019 & 2015 & 2019 \\
\hline \multicolumn{9}{|l|}{ External check scale } \\
\hline All bodies ${ }^{\mathrm{a}}$ & 0.16 & 0.12 & 1 & 1 & & & & \\
\hline Large $^{\mathrm{b}}$ & 0.27 & 0.37 & & & & & & \\
\hline Medium-sized $^{c}$ & 0.38 & -0.23 & & & & & & \\
\hline Small $^{\mathrm{d}}$ & -0.01 & 0.18 & & & & & & \\
\hline \multicolumn{9}{|c|}{ Internal administrative check scale } \\
\hline All bodies ${ }^{\mathrm{a}}$ & $0.47 * *$ & $0.48^{* *}$ & $0.26^{*}$ & $0.39 * *$ & 1 & 1 & & \\
\hline Large $^{\mathrm{b}}$ & $0.55 * *$ & $0.65 * *$ & 0.25 & $0.66^{* *}$ & & & & \\
\hline Medium-sized ${ }^{c}$ & 0.48 & 0.32 & 0.11 & -0.03 & & & & \\
\hline Small $^{\mathrm{d}}$ & $0.51^{*}$ & 0.35 & 0.32 & 0.17 & & & & \\
\hline \multicolumn{9}{|l|}{ Internal political check scale } \\
\hline All bodies ${ }^{\mathrm{a}}$ & 0.22 & 0.26 & $0.50 * *$ & $0.64 * *$ & $0.34 * *$ & $0.44^{* *}$ & 1 & 1 \\
\hline Large $^{\mathrm{b}}$ & $0.64^{* * *}$ & 0.60 ** & 0.34 & $0.59 * *$ & $0.55^{* * *}$ & $0.63 * *$ & & \\
\hline Medium-sized ${ }^{c}$ & 0.31 & 0.09 & 0.24 & $0.59 *$ & -0.11 & 0.34 & & \\
\hline Small $^{\mathrm{d}}$ & 0.03 & -0.09 & $0.65^{* *}$ & 0.53 & 0.38 & -0.06 & & \\
\hline
\end{tabular}

Table 6.

Integrating care services and external, internal administrative and political check (Pearson Correlation)
Note(s): $* p \leq 0.05 . * * p \leq 0.01$

${ }^{\mathrm{a}}$ All bodies $(2015: n=65-69,2019: n=53-57)$. ${ }^{\mathrm{b}}$ Large coordination bodies (16 or more members, 2015: $n=29$, 2019: $n=25-27)$. ${ }^{\mathrm{C}}$ Medium-sized coordination bodies (11-15 members, 2015: $\left.n=14,2019: n=17\right)$. ${ }^{\mathrm{d}}$ Small coordination bodies (10 or fewer members, 2015: $n=22-26,2019: n=11-13$ ) (see also the descriptive statistics section, Table 3) 
system since the 1980s and is still a role model in Sweden for person-centred care governance for older people, number 44 (a coordination body of a small town) has a broader scope trying to integrate care for several different groups of citizens with complex needs. The same broader scope approach characterises coordination bodies 29 and 35, which try to coordinate care within and between municipalities of a metropolitan city region. Thus, collaboration on integrating services for older people succeeds because of previous long-term progress in which as many stakeholders as possible - but with the scope restricted to the specific field of geriatric care - can themselves carry out the internal check by paying close attention to implementation centred on the older person.

\section{Discussion}

Previous research suggests two key initiatives to resolve the issues surrounding person-centred integrated care on a strategic level. One of the key variables here is sustainable collaboration by stakeholders from across the health and social care systems involved in horizontal governance and implementation (Harvey et al., 2019). The other key variable is internal democratic accountability - as perceived by a fellow collaborating body or board members - and external, more regulated vertical democratic accountability (Cooper and Grubnic, 2018). This study contributes new, systematic knowledge (beyond the case study approach), in three ways.

First, in line with a case study by Klinga et al. (2018) on how long-term, large-scale localregional collaboration has been achieved and sustained, it is suggested that such horizontal integrating care governance is systematically achieved through the key variable of collaborative consensus in the coordination body for this purpose, the target group, the leadership, communication, trust in implementation and the feeling of great quality gains from taking part. This first key variable - the governance of integrating care services scale - is repeatedly verified in 2015 and 2019 by the members of the same or corresponding coordination bodies but is only sustainable among large member coordination bodies. Thus, a large member size is important to make the governance achievement sustainable. Future research may explain why more explicitly. Second, in line with the recently summarised findings from case studies by Cooper and Grubnic (2018) on the progress of the democratic accountability of HWBs, this study further shows how monitoring and reviewing systematically evolve along two types of democratic accountability: inner or internal checks - by holding themselves to account as fellow board members - and external checks, based on a vertical or upward regulation of accountability. This second set of key variables the external and internal political and administrative accountability scales - have also been repeatedly verified by this study. Given the centralisation and regulation of democratic accountability (more than one decade of increasing hierarchy, network and market coordination policy change in Sweden), there is some evidence of a gradually growing dependence on indirect democratic accountability between external and internal checks due to previous changes in centralisation policy. Thus, the power of accountability by the external hierarchy and networks, and the use of performance information gradually seem to be connecting to the internal political and administrative behaviour of monitoring and reviewing. The lesson is that these regulative and vertical reform initiatives can contribute to democratic accountability, but the effects are indirect, limited at first and take many years to develop.

Third, in contrast to the indirect and limited effects of democratic accountability found in HWBs enforced in England by law since 2012 (Cooper and Grubnic, 2018), in Sweden, in particular, a large coordination body systematically succeeds in achieving governance of horizontal integration of care services in accordance with the level at which its key leaders 
JICA 30,5

themselves, especially as political or administrative stakeholders, carry out the monitoring and reviewing. As explained by path dependency theory (Pierson, 2000), this is due to its previous success of staying on a long-term track (trajectory), focusing only on one or the same type of integration. However, as these findings demonstrate, the real hazard and locus for future research concern those horizontal initiatives that repeatedly fail to achieve sustainable governance of integrating care services because of fewer internal checks and no relationship between governance failure and the external check.

The gap in governance and accountability of integrated care services between those strategic coordination bodies that perform well and those that do not has surfaced during the corona pandemic. In Sweden, the local and regional governments responsible for integrated eldercare have had difficulties being fully accountable for the failure to keep older people safe during the pandemic. As recently argued by Pierre (2020, p. 478) on Sweden's COVID-19 policy, "problems associated with coordinating a decentralized healthcare system, may explain the poor performance of the Swedish containment strategy." By the findings suggested in this study, it can further be argued that such poor performance is more explicitly explained by dysfunctional governance of horizontal integration of care services, as propelled by a systematic combination of weak strategic collaboration and lack of democratic partnership accountability. Differences in death rates between coordination bodies may come to correlate with weak internal check mechanisms - i.e. democratic accountability structures of internal monitor and review - and poor governance of integrating care services of the coordination body, paired with low or non-existing person-centred care.

Thus, while the quantitative longitudinal analyses show how and why sustainable governance of horizontal integration of care services in a strategic coordination body seem to be achieved systematically depending on its members' average level of democratically holding themselves to account, future research on coordination by policy-makers needs to take patient experiences more fully into account. Future research also needs to take other driving factors into the equation as the democratic accountability of governance is likely to be only one of several factors that affect the efficiency/effectiveness of integrated care services.

\section{References}

Åhgren, B. and Axelsson, R. (2011), "A decade of integration and collaboration: the development of integrated health care in Sweden 2000-2010", International Journal of Integrated Care, Vol. 11 No. 5, pp. 1-8, doi: 10.5334/ijic.566.

Anell, A., Glenngård, A.H. and Merkur, S. (2012), "Sweden: health system review", Health Systems in Transition, Vol. 14 No. 5, pp. 1-159, available at: https:/www.euro.who.int/_data/assets/pdf_ file/0008/164096/e96455.pdf (accessed 1 October 2020).

Bovens, M. (2010), "Two concepts of accountability: accountability as a virtue and as a mechanism", West European Politics, Vol. 33 No. 5, pp. 946-967, doi: 10.1080/01402382.2010.486119.

Collaboration in Discharge from Hospital Care Act (Sweden) (2017), 612, available at: https://www. riksdagen.se/sv/dokument-lagar/dokument/svensk-forfattningssamling/lag-2017612-omsamverkan-vid-utskrivning-fran_sfs-2017-612 (accessed 3 June 2020).

Cooper, S. and Grubnic, S. (2018), "Discharging democratic accountability: the role of strategy and performance information in local authority health and wellbeing boards", CIMA Research Executive Summary, Vol. 14 No. 5, pp. 1-13, available at: https:/www.cimaglobal.com/ Research-Insight/Discharging-democratic-accountability-The-role-of-strategy-andperformance-information-in-local-authority-Health-and-Wellbeing-Boards/ (accessed 20 September 2020).

Dickinson, H. (2014), "Making a reality of integration: less science, more craft and graft", Journal of Integrated Care, Vol. 22 Nos 5-6, pp. 189-196, doi: 10.1108/JICA-08-2014-0033. 
Goodwin, N., Smith, J., Davies, A., Perry, C., Rosen, R., Dixon, A., Dixon, J. and Ham, C. (2012), Integrated Care for Patients and Populations: Improving Outcomes by Working Together, The King's Fund and the Nuffield Trust, London, available at: http://www.kingsfund.org.uk/ publications/future_forum_report.html (accessed 9 June 2020).

Harvey, G., Dollard, J., Marshall, A. and Murthy Mittinty, M. (2019), "Creating the right sort of ship to achieve integrated care: a response to recent commentaries", International Journal of Health Policy Management, Vol. 8 No. 5, pp. 317-318, doi: 10.15171/ijhpm.2019.04.

Jackson, M. (2009), "Responsibility versus accountability in the Friedrich-Finer debate", Journal of Management History, Vol. 15 No. 1, pp. 66-77, doi: 10.1108/17511340910921790.

Kjellberg, I. and Szücs, S. (2020), "Pursuing collaborative advantage in Swedish care for older people: stakeholders' views on trust”, Journal of Integrated Care, Vol. 28 No. 3, pp. 231-241, doi: 10.1108/ JICA-01-2020-0001.

Klinga, C., Hasson, H., Aandreen Sachs, M. and Hansson, J. (2018), "Understanding the dynamics of sustainable change: a 20-year case study of integrated health and social care", BMC Health Services Research, Vol. 18 No. 400, pp. 1-12, doi: 10.1186/s12913-018-3061-6.

Meagher, G. and Szebehely, M. (2013a), "Long-term care in Sweden: trends, actors and consequences”, in Ranci, C. and Pavolini, E. (Eds), Reforms in Long Term Care Policies in Europe: Investigating Institutional Change and Social Impacts, Springer, New York, NY, pp. 55-78, doi: 10.1007/978-14614-4502-9_3.

Meagher, G. and Szebehely, M. (Eds), (2013b), "Marketisation in Nordic eldercare: a research report on legislation, oversight, extent and consequences”, Stockholm Studies in Social Work, Department of Social Work, Stockholm University, Stockholm, Vol. 30.

Nolte, E. and Pitchforth, E. (2014), "What is the evidence on the economic impacts of integrated care?", available at: www.euro.who.int/_data/assets/pdf_file/0019/251434/What-is-the-evidence-onthe-economic-impacts-of-integrated-care.pdf?ua $=1$ (accessed 15 June 2020).

Olsen, J.P. (2015), "Democratic order, autonomy, and accountability", Governance, Vol. 28 No. 4, pp. 425-440, doi: 10.1111/gove.12158.

Peters, B.G. (2015), The Pursuit of Horizontal Management. The Politics of Public Sector Coordination, University Press of Kansas, Lawrence, KS.

Pierre, J. (2020), “Nudges against pandemics: Sweden's COVID-19 containment strategy in perspective", Policy and Society, Vol. 39 No. 3, pp. 478-493, doi: 10.1080/14494035.2020.1783787.

Pierson, P. (2000), "Increasing returns, path dependence, and the study of politics", American Political Science Review, Vol. 94 No. 1, pp. 251-266, doi: 10.2307/2586011.

Public Choice Legislation Act (Sweden) (2008), 962, available at: https://www.riksdagen.se/sv/ dokument-lagar/dokument/svensk-forfattningssamling/lag-2008962-om-valfrihetssystem_sfs2008-962 (accessed 3 June 2020).

SOU (Swedish Government Official Report) (2016), "Effektiv vård [efficient care]", available at: http:// www.sou.gov.se/wp-content/uploads/2016/01/SOU-2016_2_Hela4.pdf (accessed 17 September 2020).

Szücs, S. (2018a), "Explaining collaborative performance success: the case of multiple constituencies' coordination bodies for frail older persons in Sweden", Paper Presented at the European Group for Public Administration (EGPA) Annual Conference, 5-7 September, Université de Lausanne, Lausanne, available at: https://www.gu.se/forskning/sqc-sustainable-quality-coordination-howto-coordinate-governance-of-social-services-and-health-care-for-frail-older-persons (accessed 14 December 2020).

Szücs, S. (2018b), "Politics of horizontal public sector coordination - the case of public policy for frail older persons in Sweden 2008-18", Paper Presented at the European Consortium for Political Research (ECPR) General Conference, 22-25 August, Universität Hamburg, Hamburg, available at: https://www.gu.se/forskning/sqc-sustainable-quality-coordination-how-to-coordinate-

\section{Horizontal integration of care services}


JICA

30,5

82

governance-of-social-services-and-health-care-for-frail-older-persons (accessed 14 December 2020).

Szücs, S. (1995), "Democratization and the reorganization of the welfare state", The Annals of the American Academy of Political and Social Science, Vol. 540, pp. 105-117, doi: 10.1177/ 0002716295540000009 .

S2011/11027/FST, "Government Offices of Sweden. approval of an agreement on a coherent integrated care for frail older persons", in Swedish, available at: https://www.regeringen.se/ overenskommelser-och-avtal/2011/12/s201111027fst/ (accessed 17 September 2020).

\section{Corresponding author}

Stefan Szücs can be contacted at: stefan.szucs@socwork.gu.se

For instructions on how to order reprints of this article, please visit our website: www.emeraldgrouppublishing.com/licensing/reprints.htm Or contact us for further details: permissions@emeraldinsight.com 